\title{
SURGICAL APPROACHES FOR DOUBLE-OUTLET RIGHT VENTRICLE OR TRANSPOSITION OF THE GREAT ARTERIES ASSOCIATED WITH STRADDLING ATRIOVENTRICULAR VALVES
}

Alain Serraf, $\mathrm{MD}^{\S}$

Tomohiro Nakamura, $\mathrm{MD}^{\S}$

François Lacour-Gayet, $\mathrm{MD}^{\S}$

Dominique Piot, $\mathrm{MD}^{\S}$

Jacqueline Bruniaux, $\mathrm{MD}^{\S}$

Anita Touchot, $\mathrm{MD}^{\S}$

Miguel Sousa-Uva, MD ${ }^{\S}$

Lucile Houyel, $\mathrm{MD}^{\S}$

Claude Planché, MD
The surgical management of patients with double-outlet right ventricle or transposition of the great arteries and straddling atrioventricular valves remains a subject of controversy. Biventricular repair has theoretic advantages because it establishes normal anatomy and physiology. In some instances, however, it seems to carry too high operative risk, and a univentricular heart repair is preferred. Since 1984, we have operated on 34 patients with double-outlet right ventricle $(n=15)$ or transposition of the great arteries $(n=19)$ with isolated straddling tricuspid valve $(n=17)$, isolated straddling mitral valve $(n=9)$, both mitral and tricuspid straddling $(n=2)$, or abnormal insertion of tricuspid $(n=7)$ or mitral $(n=2)$ chordae in the left ventricular outlet, precluding an adequate tunnel construction. Straddling was categorized according to the location of the papillary muscle insertion in the opposite ventricular chamber: type $A$, on the edge of the ventricular septal defect $(n=14)$; type $B$, on the opposite side of the ventricular septum away from the edge of the defect $(n=8)$; type $C$, on the free wall of the opposite ventricular chamber $(n=8)$. Abnormal chordal insertions were classified according to the location of their attachments around the edges of the defect. Three types of chordal distribution were identified: on the aortic conus, on the pulmonary conus crossing the ventricular septal defect, or around the defect closing it like a curtain. All but three patients had two ventricles of adequate size. Sixteen patients underwent palliation. Median age at the definitive operation was 6.5 months (range 1 to 130 months). Thirty patients underwent a biventricular repair and four had a univentricular repair. Biventricular repair was achieved by an arterial switch operation in 18 patients and by tunnel construction from the left ventricle to the aorta in 12 . In isolated straddling of types $A$ and $B$, the ventricular septal defect was closed by adjusting the septal patch on the ventricular side above the straddled papillary muscle. In type $\mathrm{C}$, the patch was sewn over the papillary muscle by applying it on the septum. In double straddling, the ventricular septum was incised between the two papillary muscles, and an ellipsoid patch was used to reconstruct the septal defect, directing each subvalvular apparatus into its own ventricular chamber. When the abnormal chordae in the left outflow tract inserted on the aortic or pulmonary conus, the conus was incised and tailored to make a flap, leaving an unobstructed left ventricular outflow
From the Department of Pediatric Cardiac Surgery (Professor Claude Planché), Marie-Lannelongue Hospital, Le PlessisRobinson, France.

Read at the Seventy-fifth Annual Meeting of The American Association for Thoracic Surgery, Boston, Mass., April 23-26, 1995.

Address for reprints: Alain Serraf, MD, Department of Pediatric
Cardiac Surgery, Marie-Lannelongue Hospital, 133 avenue de la Résistance, 92350, Le Plessis-Robinson, France.

J Thorac CARdiovasc Surg 1996;111:527-35

sy invitation.

Copyright (C) 1996 by Mosby-Year Book, Inc.

$0022-5223 / 96 \$ 5.00+0 \quad \mathbf{1 2 / 6 / 6 9 9 5 1}$ 
tract. In two patients the subvalvular apparatus was resected and reattached to the patch. Curtainlike chordae were a contraindication to biventricular repair in double-autlet right ventricle but not in transposition. There were four early deaths and one late death, all occurring in the group having biventricular repair. Death was due to myocardial ischemia $(n=1)$, right ventricular hypoplasia $(n=1)$, pulmonary hypertension $(n=$ 1 ), and residual subaortic stenosis $(n=1)$. Two patients had moderate to severe postoperative atrioventricular valve incompetence, caused by a cleft in the mitral valve in one patient. Three patents were reoperated on for subaortic stenosis $(n=1)$, pulmonary stenosis $(n=1)$, and mitral regurgitation $(n=1)$. Mean follow-up of $30.7 \pm 19.4$ months was achieved in the survivors. All but one patient (univentricular repair) were in New York Heart Association class I, without atrioventricular valve incompetence. Actuarial survival at 4 years was $85.3 \% \pm 3 \%$. We conclude that straddling or abnormal distribution of chordae tendineae of the atrioventricular valves does not preclude biventricular repair in double-outlet right ventricle or transposition of the great arteries provided that the ventricles are of adequate size. Curtainlike abnormal tricuspid chordae remain a contraindication to biventricular repair in double-outlet right ventricle. (J Thorac Cardiovasc Surg 1996;111:527-35)

C omplex malformations of the atrioventricular (AV) valve and subvalvular apparatus have been recognized as limiting factors for successful biventricular repair when associated with anomalies of ventriculoarterial connections, namely, double-outlet right ventricle (DORV) and transposition of the great arteries (TGA). ${ }^{1,2}$ The goals in performing a biventricular repair are to obtain a circulation in series with unobstructed intraventricular and extraventricular pathways. At times, achieving these goals necessitates intracardiac resections for enlargement of the ventricular septal defect (VSD), construction of complex intracardiac baffles, and extensive AV valvular or subvalvular mobilization. ${ }^{3,4}$ Moreover, extracardiac conduits and arterial or atrial switch procedures are often required in these patients. All these demanding techniques are likely to lengthen the crossclamping time, with a subsequent difficult postoperative course and a high reoperation rate. For all these reasons, the Fontan operation has been advocated on the assumption that it carries a lower operative risk than biventricular repair. ${ }^{1,2,5}$

At Marie-Lannelongue Hospital, we have been reluctant to apply Fontan's principle in patients with two ventricles of adequate size. All patients with complex intracardiac and extracardiac anatomy are scheduled for a biventricular repair unless not feasible. The single absolute limiting factor for biventricular repair is the respective size of each ventricle.
Therefore, the anatomy of the AV valve apparatus has not been a contraindication for such repair, nor has the anatomy of the ventriculoarterial connections.

Herein we report our experience with the biventricular approach in patients with anomalies of the AV valve apparatus, namely, straddling AV valve or abnormal chordal attachment precluding construction of an unobstructed intraventricular pathway, associated with DORV or TGA (or both).

\section{Patients and methods}

Anatomic definitions

$A V$ valves. The definition of straddling $\mathrm{AV}$ valves used in this report is in accordance with that proposed by Milo and associates ${ }^{6}$ : a valve whose orifice was committed to two ventricular chambers and was overriding, in contrast to a valve whose tension apparatus arose from both sides of the ventricular septum and was straddling. Each condition can exist alone or in association with the other. Classification of the type of straddling was in accordance with the recommendations of Tabry and colleagues. ${ }^{1}$ The attachment of the chordae or papillary muscle that crosses the VSD into the opposite ventricle may be near the VSD (type A), further away and inferior to the VSD (type B), or attached to the endocardial surface of the free wall of the inappropriate ventricle (type $\mathrm{C}$ ). Abnormal chordal attachments of the tricuspid valve were classified according to the description of Huhta and coworkers. ${ }^{2}$

Ventricular chambers and AV connections. In this report, we kept the usual nomenclature for right and left ventricles, and we did not follow the descriptive terms proposed by Milo and associates, ${ }^{6}$ mainly because all but 
Table I. Anatomy of patients

\begin{tabular}{|c|c|c|}
\hline & $T G A$ & DORV \\
\hline No. & 19 & 15 \\
\hline Age (median, months) & 3 & 21 \\
\hline $\operatorname{Sex}(M / F)$ & $11 / 8$ & $5 / 10$ \\
\hline \multicolumn{3}{|l|}{ AV connection } \\
\hline Concordant & 18 & 15 \\
\hline Discordant & 0 & 0 \\
\hline Criss-cross & 1 & 0 \\
\hline \multicolumn{3}{|l|}{ Straddling AV valve } \\
\hline Tricuspid & 13 & 6 \\
\hline Type A & 7 & 3 \\
\hline Type B & 3 & 1 \\
\hline Type C & 3 & 2 \\
\hline Mitral & 6 & 5 \\
\hline Type A & 2 & 2 \\
\hline Type B & 3 & 1 \\
\hline Type C & 1 & 2 \\
\hline Abnormal tricuspid attachments & 0 & 7 \\
\hline \multicolumn{3}{|l|}{ VSD } \\
\hline Perimembranous extension & 10 & \\
\hline Trabecular extension & 8 & \\
\hline Inlet & 19 & \\
\hline Subaortic & & 5 \\
\hline Subpulmonary & & 6 \\
\hline Noncommitted & & 4 \\
\hline Multiple & 5 & 1 \\
\hline \multicolumn{3}{|l|}{ Right ventricle } \\
\hline Normal & 13 & 15 \\
\hline Hypoplastic & 3 & 0 \\
\hline Pulmonary stenosis & 2 & 1 \\
\hline Aortic coarctation & 1 & 4 \\
\hline Subaortic stenosis & 0 & 3 \\
\hline
\end{tabular}

three patients had two ventricles of adequate size. The ventricular sizes were assessed by echocardiography and angiography. Therefore, the AV connections were described in the usual manner. None of the patients had discordant or common AV connections.

Patients. Since 1984, 15 patients with DORV and 19 with TGA who had associated straddling of the AV subvalvular apparatus or abnormal chordal insertion in the future left ventricular outflow tract (LVOT) were referred to Marie-Lannelongue Hospital for surgical repair. They comprised 16 boys and 18 girls. The median age at definitive operation was 6.5 months (range 1 to 130 months) and the mean weight was $8.3 \pm 4.2 \mathrm{~kg}$. Previous palliative operations had been performed in 16 patients. Primary repair was performed in 19 patients, five of whom were neonates.

Anatomic findings. Nineteen patients had TGA and single $(n=14)$ or multiple VSDs $(n=5)$. All VSDs were of the inlet type, but they extended into the perimembranous septum in seven and into the muscular septum in 10 (eight in the midtrabecular location and two in a high trabecular location). Two patients had $\{\mathrm{S}, \mathrm{D}, \mathrm{L}\}$ TGA and the others had $\{S, D, D\}$ TGA. Pulmonary valve stenosis was present in three patients, isthmic aortic coarctation in one, moderate hypoplasia of the right ventricle in two, and a criss-cross AV relationship in one. Anatomy of the AV
Table II. Surgical techniques for ventriculoarterial reestablishment

\begin{tabular}{lrccc}
\hline & TGA & DORV & $\begin{array}{c}\text { No. of } \\
\text { deaths }\end{array}$ & $\begin{array}{c}\text { No. of } \\
\text { reoperations }\end{array}$ \\
\hline $\begin{array}{l}\text { Biventricular repair } \\
\quad \text { Arterial switch } \\
\quad \text { operation }\end{array}$ & 16 & 2 & 3 & 0 \\
$\quad \begin{array}{l}\text { Intraventricular repair } \\
\text { Univentricular repair }\end{array}$ & 0 & 12 & 1 & 3 \\
\hline
\end{tabular}

valvular and subvalvular apparatus was demonstrated by echocardiography and color Doppler studies and confirmed at operation (Table I). Straddling of the tricuspid valve was demonstrated in 13 patients; six other patients had straddling of the mitral valve, one of whom had an associated cleft of the anterior mitral leaflet.

Fifteen patients had DORV. In six patients the VSD was subpulmonary; it was subaortic in five, all with inlet extension; and it was noncommitted in four. Three patients had a subaortic stenosis caused by a restrictive VSD and by straddling of both the tricuspid and mitral valves. One had multiple VSDs. The anatomy of the AV valvular and subvalvular apparatus was demonstrated by echocardiography and color Doppler studies and confirmed at operation (see Table I). Five patients had isolated straddling of the tricuspid valve, four had isolated straddling of the mitral valve, two had double straddling of the tricuspid and the mitral valves, and seven patients had abnormal insertion of the tricuspid chordae on the future LVOT pathway. Finally, three patients also had a cleft mitral valve. One patient had pulmonary valvular stenosis and three had an aortic coarctation.

Surgical procedures (Table II). Repair was undertaken in all patients under continuous hypothermic cardiopulmonary bypass. Myocardial protection was achieved by repeated infusions of blood cardioplegic solution into the aortic root. The mean crossclamp time was $87.4 \pm 26.4$ minutes and the mean cardiopulmonary bypass time was $150.6 \pm 39.2$ minutes. Anatomic biventricular repair was planned in all cases. In four patients, intracardiac exploration revealed right ventricular hypoplasia more significant than had been expected in three patients, and very complex subvalvular anatomy of both the mitral and tricuspid valves in one. During the operation, therefore, these patients were switched to a univentricular heart repair program. All the other patients underwent anatomic biventricular repair either by an arterial switch operation $(n=18)$ or by construction of a tunnel between the left ventricle and the aorta $(n=12)$. Indications for the arterial switch operation or intraventricular repair have already been discussed elsewhere. ${ }^{7,8}$ In brief, patients with mitral-aortic discontinuity and aortic overriding of more than $50 \%$ of the right ventricle were candidates for an intraventricular repair. Whether to perform an arterial switch operation $(n=2)$ or a Kawashima procedure $(n=3)$ in patients with Taussig-Bing hearts was based on previously described criteria. During intraventricular rerouting, enlargement of the VSD $(n=7)$ was based on preoperative existence of a subaortic ob- 


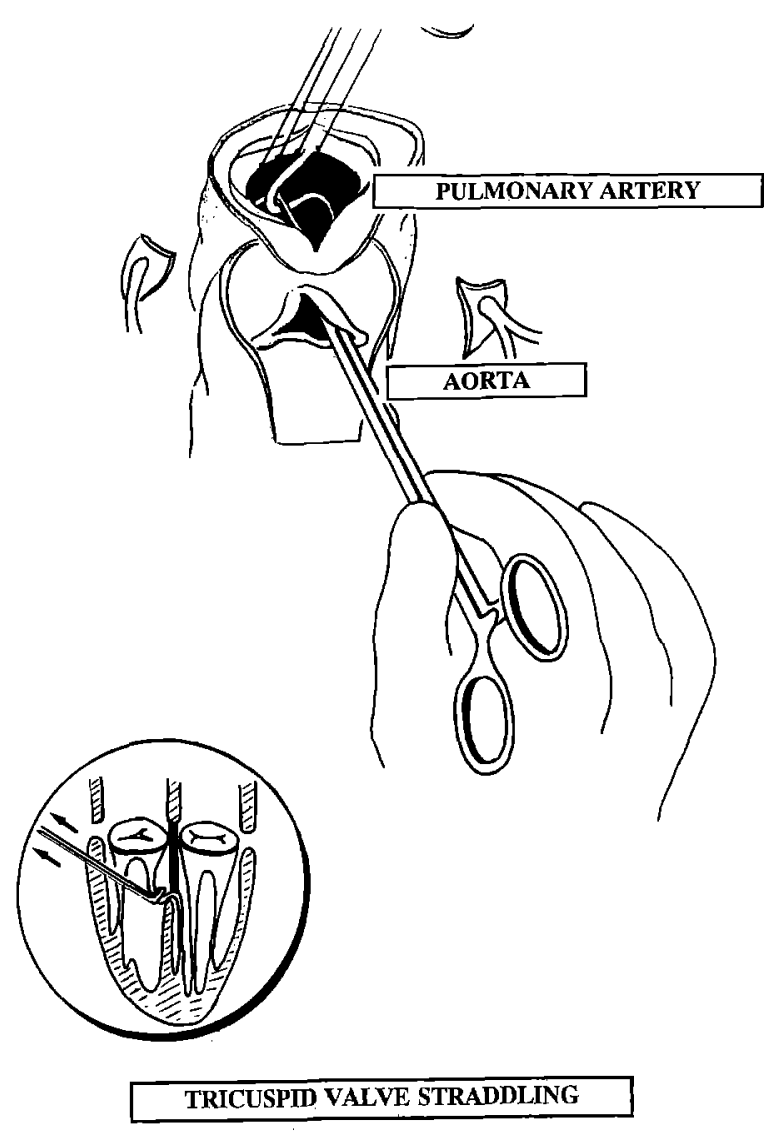

Fig. 1. Surgical technique for intraoperative management of straddling tricuspid valve in TGA. After section of the great arteries, the intracardiac anatomy is explored through the semilunar valves. The chordae or the papillary muscle crossing the VSD into the left ventricular cavity is retracted toward the right ventricle by a hook passed through the native aortic valve. The VSD is then closed through the native pulmonary valve in the usual manner. Sometimes it is necessary to complete this procedure through the right atrium.

struction and the surgeon's discretion to obtain an appropriate intraventricular baffle. ${ }^{10}$

Closure of VSD in TGA and straddling AV valve. After the great arteries were sectioned, the intracardiac anatomy was explored through the semilunar valves. This approach allowed clear exposure of the septum and the VSD even when it was primarily an inlet type. In some patients the lower edge of the VSD or the entire VSD was exposed through a right atriotomy. In the presence of a straddling tricuspid valve, after identification of the anatomic structures, the chordae or the papillary muscle crossing the VSD into the left ventricular cavity was retracted toward the right ventricle by a hook passed through the native aortic valve (Fig. 1). The VSD was then closed through the native pulmonary valve in the usual manner. Sometimes it was necessary to complete this procedure through the right atrium. In the presence of a

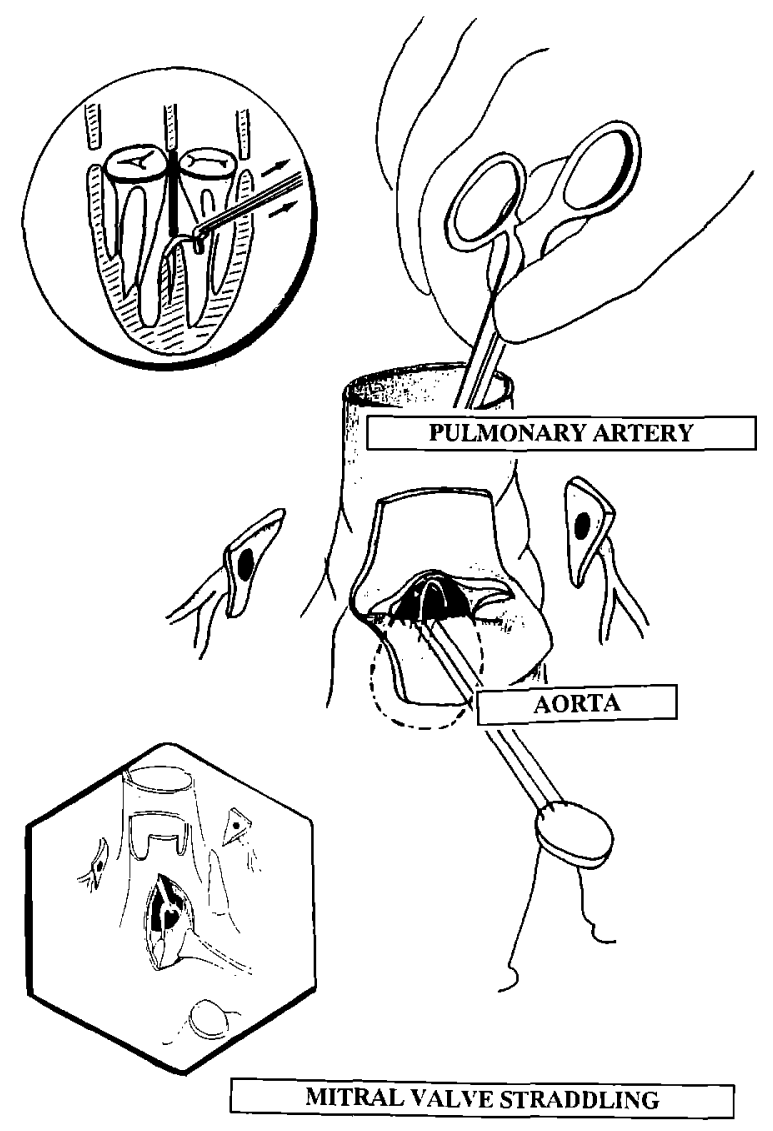

Fig. 2. Surgical technique for intraoperative management of straddling mitral valve in TGA. The chordae or the papillary muscle is retracted into the left ventricle with a hook passed through the native pulmonary artery. The VSD is then closed either through the native aortic valve or through a right ventriculotomy. It is sometimes necessary to complete this procedure through the right atrium.

straddling mitral valve, the same technique was used. The chordae or the papillary muscle was retracted into the left ventricle with a hook passed through the native pulmonary artery. The VSD was then closed either through the native aortic valve or through a right ventriculotomy (Fig. 2). In one patient with double straddling, these techniques were not suitable. Therefore, through a right ventriculotomy, the ventricular septum was incised between the two papillary muscles and an ellipsoid patch was used to close the VSD, so that each papillary muscle was placed in its own ventricular chamber.

Construction of the LVOT tunnel in DORV and straddling $A V$ valve. In this subset of patients, the intracardiac anatomy was always explored through a right ventriculotomy. This approach allowed for identification of the edges of the VSD and the subvalvular structures in all cases. Several abnormalities of the subvalvular apparatus were encountered: isolated straddling of the tricuspid or mitral valves, double straddling of the tricuspid and mitral valves, and abnormal insertion of the chordae tendineae of the 
tricuspid valve on the outlet septum. The chordae tendineae were found to insert on the aortic conus, on the pulmonary conus, or all around the VSD. In the presence of a straddling tricuspid valve, again the chordae or the papillary muscle was gently retracted toward the right ventricular cavity and the tunnel was constructed by sewing the inferior rim of the patch to the left ventricular aspect of the VSD. In type B straddling, the septum was incised close to the insertion of the papillary muscle, which transformed it into type $A$. In two patients, however, the chordae were sectioned at their muscular insertion and were secondarily reimplanted on the tunnel patch. In the presence of a straddling mitral valve, the chordae or the papillary muscle crossing the VSD was left untouched and incorporated in the LVOT by sewing the patch around the right ventricular insertion. Abnormal insertion of the chordae of the tricuspid valve on the outlet septum was managed by tailoring myocardial flaps so that an unobstructed pathway was left for tunnel construction (Fig. 3). One patient had double straddling of the tricuspid and mitral valves associated with abnormal insertion of the remaining tricuspid chordae. In this case, biventricular repair was believed to carry too high a morbidity, and after closure of the right ventriculotomy a bidirectional Glenn anastomosis was used for palliation

Reconstruction of the right ventricular outflow tract (RVOT). The Lecompte maneuver was used in all the patients undergoing an arterial switch operation. The neopulmonary trunk was reconstructed with an autologous fresh pericardial patch. Among patients who underwent intraventricular rerouting, the RVOT was reconstructed with an extracardiac valved conduit in two who had severe pulmonary stenosis; an infundibular patch was used in four who had infundibular stenosis caused by pulmonary valve stenosis or pulmonary artery banding; and a transannular patch was used in one.

Follow-up and statistical analysis. Follow-up was $100 \%$ in all survivors. Cardiac function was analyzed by serial echocardiographic and color Doppler studies with particular attention to $\mathrm{AV}$ valve function, subaortic area, and ventricular function. The median follow-up was 27 months (range 6 to 76 months). Survival was analyzed according to Kaplan-Meier methods. Ratios are expressed with $70 \%$ confidence limits (CL).

\section{Results}

Mortality. Four early deaths and one late death occurred, all after attempted biventricular repair (postoperative mortality $13.3 \%, 70 \% \mathrm{CL} 6 \%$ to $22.9 \%$ ). The causes of death at postmortem examination were myocardial infarction after an arterial switch operation in one patient, severe right ventricular hypoplasia in one, and acute and irreversible pulmonary hypertensive crises in one. The remaining patient who died after the operation had DORV and straddling mitral valve. The straddling papillary muscle was incorporated in the subaortic tunnel and caused a severe subaortic obstruction. The tech-

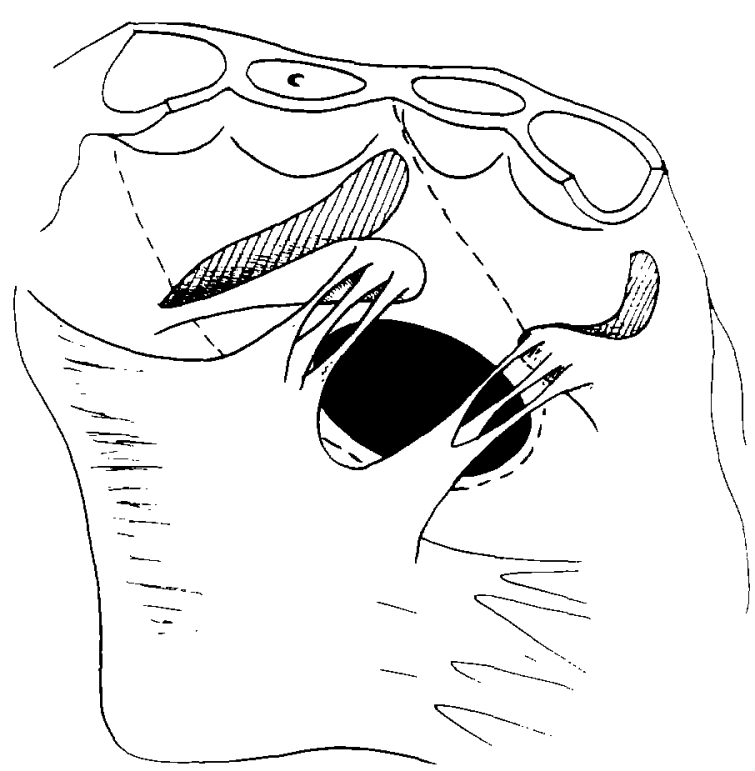

Fig. 3. Surgical technique for tailoring of the myocardial flap in the presence of abnormal attachments of the tricuspid valve on the outlet septum in DORV.

nique failed in this last patient, but the three others did not have any AV valve lesion resulting from the operation at postmortem examination.

Follow-up of the survivors was conducted by the referring pediatric cardiologists. The mean followup period was $30.6 \pm 19.7$ months. Attention was particularly oriented toward AV valve function and the subaortic area, in addition to the standard examinations after such procedures. Small residual VSDs were present in 10 patients. They were located mostly in the area of the patch that was oversewn over the straddling chordae. However, none of these residual VSDs were responsible for a significant left-to-right shunt.

Thirteen patients had some degree of valvular dysfunction. Isolated tricuspid insufficiency was trivial in two patients, moderate in two, and severe in one. Isolated mitral insufficiency was trivial in one, moderate in two, and severe in one patient with a cleft anterior leaflet. Three others had both mitral and tricuspid incompetence, trivial in one and moderate in two. All the others had good valvular function without leak or stenosis.

All but three patients had an unobstructed left ventricular pathway. One with TGA and straddling tricuspid valve and two with DORV and abnormal insertion of tricuspid chordae had mild to severe subaortic stenosis with a mean peak systolic gradient 


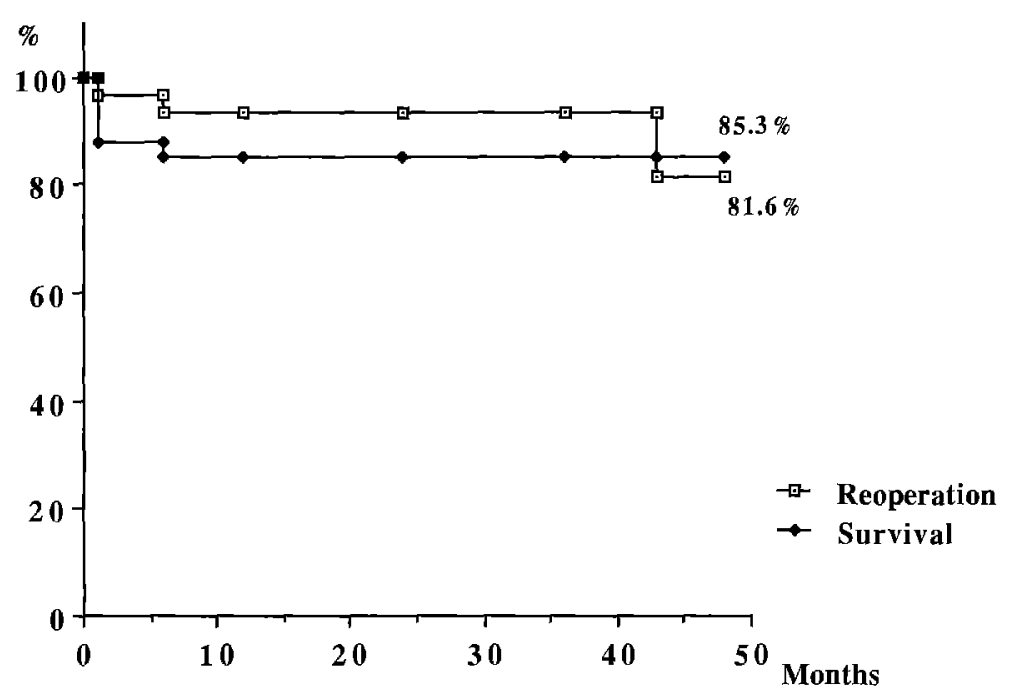

Fig. 4. Actuarial survival and freedom from reoperation at 4 years.

between the left ventricle and the aorta of $50 \mathrm{~mm}$ $\mathrm{Hg}$.

Complete AV block occurred in one patient with criss-cross AV relationship, multiple VSDs, L-TGA, and straddling of the tricuspid valve.

All but one of the survivors were in New York Heart Association class I at the most recent clinical examination without medication. One patient with DORV, double straddling of the tricuspid and mitral valves, and abnormal chordal insertion on the outlet septum 2 years after a bidirectional Glenn anastomosis had severe left ventricular dysfunction that improved slightly with afterload reduction medication.

Reoperations. Four patients underwent six reoperations with a median delay of 16.6 months and no deaths. In one patient with DORV and abnormal insertion of tricuspid chordae on the outlet septum, there was initially no gradient between the left ventricle and the aorta, but later a subaortic stenosis developed with a gradient progressing up to $80 \mathrm{~mm}$ $\mathrm{Hg}$. At reoperation, the upper insertion of the baffle around the aortic anulus seemed to be constricting. Tailoring of the myocardial flaps including the abnormal chordae had not caused stenosis. The patch was partially taken down and was replaced with a larger one. Postoperatively, the gradient between the left ventricle and the aorta fell to $15 \mathrm{~mm} \mathrm{Hg}$.

Severe mitral incompetence developed in another patient, who had Taussig-Bing heart and a straddling mitral valve. At reoperation, a cleft in the anterior leaflet was found and sutured, and a mitral annuloplasty was done with a Carpentier ring. One patient also had DORV, straddling tricuspid valve, pulmonary stenosis, and diminutive pulmonary artery branches. At the first operation he underwent intraventricular rerouting, with a transannular patch being used to reconstruct the RVOT. One month later he had severe tricuspid incompetence, residual VSD, and severe pulmonary valve incompetence. At reoperation, the residual VSD associated with the tricuspid annuloplasty was closed and the RVOT was reconstructed with a valved homograft. The postoperative course was uneventful. The last patient, already mentioned, had criss-cross AV relationship, multiple VSDs, L-TGA, and straddling of the tricuspid valve. An arterial switch operation with closure of the VSDs resulted in a large residual VSD and complete AV block. He was first reoperated on for pacemaker insertion and pulmonary artery banding because of the complex anatomy of the interventricular septum. One year later he successfully underwent closure of the residual defect.

Four years postoperatively, actuarial survival and freedom from reoperation for patients undergoing a biventricular repair were $85 \% \pm 3 \%$ and $70.0 \% \pm$ $15 \%$, respectively (Fig. 4 ).

\section{Discussion}

This series comprised patients with complex AV valve anatomy and abnormal ventriculoarterial connections, but two adequately developed ventricles. Biventricular repair proved to be feasible in $88 \%$ of them (30/34). Moreover, in three of the 34 patients the right ventricular hypoplasia was more significant than expected; therefore these patients should have 
been excluded from a biventricular heart repair program or should have been managed with biventricular repair associated with a bidirectional Glenn anastomosis. ${ }^{11,12}$ Indeed, right ventricular hypoplasia has been reported to be frequently associated with anomalies of the AV valves such as overriding or straddling ${ }^{13,14}$ and is probably related to a regional malformation of the sinus portion of the ventricular septum. On the other hand, straddling $\mathrm{AV}$ valves are frequently reported in univentricular hearts. ${ }^{15}$ We consider the extent of ventricular hypoplasia to be a limiting factor for biventricular repair, one-and-one-half ventricular repair, or univentricular repair. We do not have enough data in these different subgroups to clearly define the surgical indications between the type of repair and the magnitude of ventricular hypoplasia. However, if one assumes that the venous return through the inferior vena cava accounts for two thirds of the systemic venous return, a hypoplastic right ventricle two-thirds normal in size should tolerate a one-andone-half ventricular repair. With a lesser degree of hypoplasia, biventricular repair is indicated, whereas a greater degree warrants a univentricular heart repair. The other contraindication to biventricular repair of DORV in this series was the existence of abnormal chordal insertion all around the VSD edges, similar to a curtain, which renders the construction of a baffle unfeasible without high risk of valvular incompetence.

Straddling tricuspid valve was initially described by Rastelli, Ongley, and Titus ${ }^{4}$ in complete AV canal defects. It was then reported with a high frequency in patients with single ventricle in whom the intraventricular anatomy was not clearly described. More recently, surgical attempts at closure of the VSD in an anatomic subset of patients who had two ventricles of equal size were published. ${ }^{16,17}$ In these surgical reports the VSD was not necessarily located purely in the inlet portion of the ventricular septum, but all of the the VSDs had an inlet extension. Moreover, variations in the location of the VSD have been described in association with abnormal ventriculoarterial connection. This feature was particularly true for straddling of the mitral valve in association with Taussig-Bing hearts. ${ }^{14}$ Review of our patient's echocardiograms and operative reports demonstrated that straddling AV valves can exist in association with several types of VSDs. However, when the tricuspid valve straddles or overrides, there is a constant inlet extension of the septal defect, which is not observed in straddling of the mitral valve.
Several surgical techniques for repair in such anatomic conditions have been reported. ${ }^{1,3,4,14,16,17}$ They all pointed out the high risk of complete AV blocks. Milo and associates ${ }^{6}$ showed that conduction pathways do not arise from regularly situated AV nodes and that in biventricular hearts with normal AV connections the crux should be free from conduction tissue. In the present series there was a low incidence of AV block (3.8\%). No particular attention was given to the possible variations of the conduction pathways. However, all usual precautions to avoid conduction tissue during the operation were taken. In hearts with TGA, when the VSD was closed through the neoaortic valve, very fine endocardial sutures were first placed on the left ventricular aspect of the septum away from the edges of the VSD and then into the patch. This technique has now been applied in more than 200 patients with TGA and VSD and has been effective for avoidance of the conduction pathway and for closure of the VSD, assuming that the left ventricular pressure will further push the patch onto the septum. We therefore strongly believe that the anatomy of the conduction pathway in the setting of straddling AV valves and VSD follows the same descriptive features as in hearts with a VSD but without straddling AV valves and that similar precautions to avoid injury should be used.

The technique for intraoperative management of straddling AV valves proposed in this work is simple and reproducible. Retraction of the abnormal chordae or papillary muscle toward the anatomically related ventricular chambers and closure of the VSD on the opposite side of the septum was previously proposed by Tabry and associates ${ }^{1}$ and by Pacifico, Soto, and Bargeron ${ }^{16}$ for straddling types A and $B$. For straddling type $C$, these authors did not recommend this technique. However, it was used in seven patients of the current series with straddling type $\mathrm{C}$ malformations. Interestingly, the preoperative type of straddling could not be identified by the echocardiographic Doppler studies done after repair without use of the preoperative echocardiograms for comparison.

There were few problems related to the valve during the immediate and long-term follow-up. Only two patients required reoperation for valvular incompetence, one on the tricuspid valve and the other on the mitral valve. In one case, the mitral incompetence was caused by a cleft. This association has been previously reported in clinical ${ }^{18}$ and patho$\operatorname{logic}{ }^{19,20}$ studies. The other case of tricuspid incom- 
petence necessitating surgical treatment occurred in one patient in whom a large transannular patch was used for reconstruction of the RVOT. Severe pulmonary valve insufficiency developed with progressive right heart enlargement and tricuspid insufficiency. Insertion of a valve in the RVOT associated with tricuspid annuloplasty was performed and the postoperative course was uneventful. Therefore, in these two cases of postoperative valvular incompetence, the causes of valve reoperation were not related to the surgical management of the straddling AV valve.

Abnormal insertion of chordae tendineae of the tricuspid valve on the outlet septum can be a source of difficulty for intraventricular repair in DORV. Rubay and associates ${ }^{21}$ described a technique of myocardial flap tailoring in cases of abnormal insertion on the infundibular septum. The conus including the chordae is partially incised and retracted backward, allowing for the usual construction of an unobstructed left ventricle-to-aorta baffle. Following the same principles, we extend this technique to patients with abnormal tricuspid attachments on the subpulmonary conus and/or on the subaortic conus. However, in one patient with complex association of straddling tricuspid and mitral valves and abnormal tricuspid attachments, it was believed at operation that the subaortic pathway could not be satisfactorily opened without comprising both $\mathrm{AV}$ valves. This patient therefore underwent a palliative bidirectional Glenn anastomosis.

Gradients across the ventricular outflow tracts can result from the protrusion of the subvalvular apparatus in the outflow tract. Gradients were the cause of preoperative subaortic stenosis in three patients and postoperative stenosis in one. Preoperatively, the subaortic gradient was due to straddling of the tricuspid and mitral valves in two patients and to a restrictive VSD in one. Postoperatively, in one instance the subaortic stenosis was clearly due to a small baffle that required enlargement 6 months later.

In conclusion, 30 of 34 patients with complex AV valve malformations associated with DORV or TGA underwent a biventricular repair. This approach was not associated with high mortality or reoperation rates. Interestingly, the $\mathrm{AV}$ valve function at a mean follow-up of 30.6 months was very satisfactory and no valve replacement was necessary. The intraoperative technique for correction of straddling was simple to perform. On the other hand, construction of a baffle between the left ventricle and aorta in the presence of abnormal tricuspid attachments requires intraventricular myocardial flap tailoring, leaving an unobstructed LVOT. The four patients who were rejected for biventricular repair had right ventricular hypoplasia $(n=3)$ and very complex anatomy of both AV valves $(n=1)$. In contrast to previous investigators, ${ }^{1,2,5}$ we do not recommend a Fontan operation in this subset of patients.

\section{Addendum}

Since the submission of this article, another 7-year-old patient with DORV, noncommitted VSD, type C tricuspid valve straddling, and $60 \%$ right ventricular hypoplasia was subjected to biventricular repair by means of the same technique. The postoperative course was uneventful.

We are grateful to Daniel Roux, MD, for his drawings.

\section{REFERENCES}

1. Tabry IF, McGoon DC, Danielson GK, Wallace RB, Tajik AJ, Seward JB. Surgical management of straddling atrioventricular valve. J THORAC CARDIOvaSC SuRg 1979;77:191-201.

2. Huhta JC, Edwards WD, Danielson GK, Feldt RH. Abnotmalities of the tricuspid valve in complete transposition of the great arteries with ventricular septal defect. J THORAC CARDIOVASC SURG 1982;83:569-76.

3. Danielson GK, Tabry IF, Ritter DG, Fulton RE. Surgical repair of criss-cross heart with straddling atrioventricular valve. J THORAC CARDIOVASC SURg 1979;77:847-51.

4. Rastelli GC, Ongley PA, Titus JL. Ventricular septal defect of atrioventricular canal type with straddling right atrioventricular valve and mitral valve deformity. Circulation 1968; $37: 816-25$

5. Russo P, Danielson GK, Puga FJ, McGoon DC, Humes R. Modified Fontan procedure for biventricular hearts with complex forms of double outlet right ventricles. Circulation 1988;78(Suppl);III20-5.

6. Milo S, Yen Ho S, Macartney FJ, et al. Straddling and overriding atrioventricular valves: morphology and classification. Am J Cardiol 1979;44:1122-34.

7. Sakata R, Lecompte Y, Batisse A, Borromée L, Durnady Y. Anatomic repair of anomalies of ventriculoarterial connection associated with ventricular septal defect. I. Criteria for surgical decision. J ThORAC Cardiovasc Surg 1988;95:90-5.

8. Aoki M, Forbess JM, Jonas RA, Mayer JE Jr, Castaneda AR Result of biventricular repair for double-outlet right ventricles. J Thorac Cardiovasc Surg 1994;107:338-50.

9. Serraf A, Lacour-Gayet F, Bruniaux $\mathbf{J}$, et al. Anatomic repair of Taussig-Bing hearts. Circulation 1991;84(Suppl):III200-5.

10. Serraf A, Lacour-Gayet F, Houyel L, et al. Subaortic obstruction in double outlet right ventricles: surgical considerations for anatomic repair. Circulation 1993;88(Pt 2):177-82.

11. Muster AJ, Zales VR, Ilbawi MN, Backer CL, Duffy CE, Mavroudis C. Biventricular repair of hypoplastic right ventricle assisted by pulsatile bidirectional cavopulmonary anastomosis. J ThoraC Cardiovasc SuRg 1993;105:112-9.

12. Gentles TL, Keane JF, Jonas RA, Marx GE, Mayer JE Jr. Surgical alternatives to the Fontan procedure incorporating a hypoplastic right ventricle. Circulation 1994;90(Pt 2):II1-6.

13. Liberthson RR, Paul MH, Muster AJ, Arcilla RA, Eckner 
FSO, Lev M. Straddling and displaced atrioventricular orifices and valves with primitive ventricles. Circulation 1971; 43:213-26.

14. De Vivie R, Van Praagh S, Bein G, Eigster G, Vogt J, Van Praagh R. Transposition of the great arteries with straddling tricuspid valve: report of two cases with acquired subaortic stenosis after main pulmonary artery banding. J THORAC CARDIOVASC SURG 1989;98:205-13.

15. Tandon R, Becker AE, Moller JH, Edwards JE. Double inlet left ventricle: straddling tricuspid valve. Br Heart J 1974;36: 747.59.

16. Pacifico AD, Soto B, Bargeron LM. Surgical treatment of straddling tricuspid valves. Circulation 1979;60:655-64.

17. Planché C, Fermont L, Bruniaux J, Sidi D, Kachaner J, Binet JP. "Straddling" de la valve tricuspide à travers une communication interventriculaire isolée. Arch Mal Coeur 1982;75: 905-14.

18. Wernovsky G, Jonas RA, Colan SD, et al. Results of the arterial switch operation in patients with transposition of the great arteries and abnormalities of the mitral valve or left ventricular outflow tract. J Am Coll Cardiol 1990;16:1446-54.

19. Aziz KU, Paul MH, Muster AJ, Idriss FS. Positional abnormalities of atrioventricular valves in transposition of the great arteries. Am J Cardiol 1979;44:1135-9.

20. Zamora R, Moller JH, Edwards JE. Double outlet right ventricle: anatomic types and associated anomalies. Chest 1975;68:672-7.

21. Rubay J, Lecompte Y, Batisse A, et al. Anatomic repair of anomalies of ventriculo arterial connection (REV). Eur $\mathrm{J}$ Cardiothorac Surg 1988;2:305-11.

\section{Discussion}

Mr. Marc R. de Leval (London, England). I should like to ask three questions. Most of the VSDs you described are merely by definition of inlet type, and I am surprised that you seem to have access to those defects from the arterial valves. Could you provide some technical details of the procedures?

The second question relates to the risk of heart block. You did not mention arrhythmias in your presentation. The conduction system in patients with, for example, DORV and straddling tricuspid valve may be abnormally situated. Similarly, I am concerned about the risk of creating heart block while closing a VSD through the pulmonary artery in TGA.

Last, I should like you to comment on the preoperative investigations and criteria of suitability for biventricular repair in patients with straddling AV valves. Would you do those operations in infancy or would you advocate palliation in the young infant before attempting complete repair?

Dr. Serraf. Thank you, Mr. de Leval. You raise the point that in the presence of straddling AV valves the VSD should be of inlet type. This was true in the group of patients with TGA, but this statement should be slightly modulated. Although all the patients had inlet VSDs, in the majority the VSDs extended into other parts of the septum. In the DORV group, five patients had noncommitted inlet VSD and four had subpulmonary VSD. In the latter form, straddling $A V$ valves have already been described. That leaves six patients with subaortic VSD, in which straddling is uncommon. How- ever, we did include patients with DORV and abnormal attachments of the tricuspid valve precluding construction of an unobstructed tunnel from the left ventricle to the aorta.

With regard to the approach for VSD closure through the semilunar valves in patients with TGA, we were not the first to describe this approach. In fact. we adopted it quite late after its introduction. We have found that the majority of VSDs could be closed easily through this approach, even those with an inlet extension. However, when the lower edge of the VSD was too far into the inlet septum, or in pure inlet VSD, it was approached through a right atriotomy. In DORV, the right ventricular approach could always reveal all the edges of the VSD.

Heart block seems to be more frequent in this situation. In the current series, only one patient with criss-cross AV relationship and multiple VSDs had an AV block. Although the conduction pathways were described as abnormal in hearts with straddling AV valves, these descriptions were made almost exclusively in univentricular hearts. No precautions other than the usual ones were taken during closure of the VSD, and it may be concluded that in biventricular hearts with abnormal AV valves the conduction pathways are almost normal. VSD closure through the pulmonary artery in TGA is now routine. Very fine sutures are placed away from the edges of the VSD and, therefore, away from the conduction pathways. We believe this technique to be safe in terms of avoiding $\mathrm{AV}$ block and closing the VSD.

With regard to your last two questions, there is no type of straddling $\mathrm{AV}$ valve that we would exclude from biventricular repair. We will be more cautious in the presence of double tricuspid and mitral straddling. The single criterion excluding a patient from biventricular repair is the respective sizes of the ventricles. The age for repair remains under debate and is highly related to the expertise of the surgeon. In TGA, neonatal repair can be done with good results. In DORV, we prefer to delay repair until the patient is older than 1 year.

Dr. Edward L. Bove (Ann Arbor, Mich.). Many of these patients with straddling valves will have hypoplasia of one ventricle. You mentioned that you had at least one death from that problem. How do you assess that situation before the operation?

Dr. Serraf. It is correct that most of the patients with this condition have hypoplasia of the right ventricle. The only means that we use to assess the size of the right ventricle is echocardiography.

Dr. Christo I. Tchervenkov (Montreal, Quebec, Cana$d a)$. How did you deal with the specific instance of type $C$ straddling, in which a papillary muscle of the tricuspid valve inserted on the free wall of the left ventricle? Did you divide the papillary muscle and reattach it inside the right ventricle?

Dr. Serraf. No, never. We retract the papillary muscle through its correlated anatomic cavity and apply the patch on the straddled papillary muscle or chordae. It is amazing that, after the operation, our cardiologists cannot recognize which patient had straddling before the operation if they did not have this information beforehand. But the single technique was to apply the papillary muscle to the patch and to the septum. 